\title{
LOS CLÁSICOS EN EL RENACIMIENTO. LA LABOR EDUCATIVA DE JUAN LUIS VIVES
}

Leticia López Serratos

UNAM, Facultad de Filosofía y Letras/Consejo Nacional de Ciencia y Tecnología, México, 2006, 240 p.

\section{DATOS SOBRE LA AUTORA}

Leticia López Serratos es licenciada, maestra y doctora en Letras Clásicas por la Facultad de Filosofía y Letras de la Universidad Nacional Autónoma de México. Actualmente realiza una estancia posdoctoral en el Centro de Estudios Clásicos del Instituto de Investigaciones Filológicas, para profundizar sus estudios sobre los clásicos del Renacimiento. Es docente del Colegio de Letras Clásicas de la Facultad de Filosofía y Letras de la Universidad Nacional Autónoma de México.

\section{CONTENIDO}

El texto se desarrolla en dos grandes apartados, más una introducción y cuatro apéndices.

En la Introducción se explica lo siguiente: cómo el humanismo surge en el Renacimiento como movimiento de renovación; las implicaciones fundamentales del término giran en torno al marco escolar, es decir, que este surge para referirse a ciertos hombres de estudio. La aportación del Humanismo consiste en restituir su valor al estudio de la literatura, además, como imperativo de toda la educación, dicho 
movimiento intelectual implica un cambio en la historia del pensamiento, con el que comienza a gestarse un ideal de educación civil en respuesta a las nuevas necesidades de la sociedad burguesa y cómo este centra su atención en la retórica, gracias a los hallazgos de nuevas obras de Cicerón y de Quintiliano.

En la Parte I, denominada «La educación en el pensamiento de Vives», la autora ofrece datos biográficos que dan cuenta de la difícil vida del autor, quien nació en Valencia el mismo año del descubrimiento de América, esto es en 1492; de su formación académica escolar nos comparte que cursó estudios generales, gramática, artes y latín, y en cuanto a su labor profesional relata también su estancia en Valencia, París, los Países Bajos e Inglaterra, así como la influencia que tuvo del Humanismo y del nominalismo para la conformación de su pensamiento educativo. Vives, como es usual en los autores que realizan reflexión educativa, tiene una intensa labor como tutor de personas de clase alta. Asimismo, con elocuente prosa, nos comenta los detalles de su colaboración con otro renombrado humanista, Erasmo de Rotterdam, con quien entabla una asidua amistad, casi siempre por medio de la tradición epistolar.

En Inglaterra, Vives se relaciona con Tomás Moro y obtiene una cátedra en Oxford, institución con la que también estrecha lazos amistosos. Vale la pena comentar aquí, que Tomás pide a Vives continuar una controversia que había escrito Quintiliano - intitulada Paries palmatus (La pared y la mano ensangrentada)—, en ella, el retórico romano defiende al ciego y Vives, después de mucha insistencia de Moro, continúa la controversia con la defensa de la madrastra. Segura estoy que los lectores que se acerquen a su lectura encontrarán interesante y divertida esta estrategia didáctica realizada por los rétores romanos [quienes escribían o enseñaban retórica] para la enseñanza del orador en la educación superior. Tiempo después, debe regresar a los Países Bajos, situación que le acarrea muchos conflictos pues la reina, de quien él es persona allegada, se divorcia de Enrique VIII.

Por cuanto toca a la visión educativa de Vives, la fuente principal de su pensamiento pedagógico es Quintiliano, lo mismo que su 
intensa experiencia como docente individual y en el plano colectivo. De dichas fuentes extrae la recomendación de que un niño de diez a doce años debe dejar su casa para ir a vivir con su «familia pedagógica», con el propósito de ser instruido y de formar su carácter; el niño debe amar y respetar al maestro como a un padre. Para Vives, la educación es un acto de reciprocidad amorosa, filial, y también lo es de transformación, pues a través de ella, la bestia se hace hombre, la bestia se humaniza.

De las aportaciones de Vives en el campo de la educación, la autora señala que, para él, la verdadera filosofía es un continuo aprendizaje sintetizado en un «aprender a vivir». De los más de veinte textos que escribe, el más importante es Tradendis disciplinis - mejor conocido como Tratado de la enseñanza-, donde fundamenta la necesidad de la educación en todos los aspectos, lo que implica una pedagogía activa del docente y un aprendizaje activo del alumno, resaltando el papel del juego.

No olvida elaborar recomendaciones sobre el emplazamiento de la escuela, que requiere ser un lugar salubre y adecuado para el estudio, no debe ser un sitio solitario pero tampoco muy concurrido, conviene que se ubique a las afueras de la ciudad y debe ser un espacio donde reine la cordialidad. El papel del maestro será el de observador, formador y transmisor, pero sobre todo, consiste en ser un ejemplo, de manera que debe ser virtuoso, sabio y proporcionar un afecto paternal.

En cuanto a la educación del alumno, Vives considera más conveniente un proceso colectivo, que lo prepara para establecer comunicación con los otros y vivir adecuadamente en sociedad. Su ideal educativo es el de formar un hombre erudito, a través del desarrollo de tres elementos: ingenio, memoria y aplicación; su realización plena se desarrolla en el contexto social, con especial énfasis en los aspectos morales y políticos, y por otro lado los lingüísticos, pues, por una parte, el hombre educado es conocedor del latín y de la gramática y, por otra, debe poseer piedad cristiana. 
En la Parte II, denominada «Vives y la enseñanza del latín y de la cultura clásica», la doctora López Serratos, menciona la importancia que para Vives reviste el estudio de la gramática de la lengua vernácula para el aprendizaje del latín, cuyo cultivo considera una disciplina mental. En dicho apartado menciona cómo Vives recomienda realizar estudios de dialéctica y retórica.

Es interesante observar, en el pensamiento del valenciano, las características de un hombre del humanismo, y por lo tanto, situado en contra de las ideas de los escolásticos medievales, quienes consideran que la ciencia se sustenta en las autoridades y que es una realidad ya dada: no tratan de transformarla, sino de transmitirla; para los escolásticos, la dialéctica es la lógica formal, y el estudio del lenguaje se realiza para engalanar discursos. Por su parte, Vives considera que el nuevo hombre, el humanista, debe volver a las fuentes clásicas para leerlas con sentido crítico; que la ciencia debe incrementarse, no solo transmitirse como ciencia acabada; el lenguaje debe entenderse como ciencia, pues es un importante acceso a los estudios literarios, que traduce el ideal educativo.

Uno de los elementos formativos para el hombre humanista, desde el punto de vista de Vives, es el trivio, es decir, el estudio de la gramática, la dialéctica y la retórica, pues el hombre refleja su educación a través del lenguaje; la dialéctica lo nutre al proporcionar solidez a los argumentos, para finalmente expresarse con elegancia a través de la retórica.

De las aportaciones de Vives en la enseñanza del latín, resalta la cuidadosa explicación de los dos grandes métodos de enseñanza: inducción y deducción, así como de los procesos cognoscitivos y los mecanismos de enseñanza-aprendizaje: procesos de observación-aprehensión. Para definir el alma racional pone atención a sus actividades, a saber: inteligencia, voluntad y memoria, y explicita las condiciones para el desarrollo de las operaciones, que son la atención y el ingenio. 
Un elemento trascendental para Vives es el programa para la enseñanza de la lengua, organizada en los siguientes rubros: fonética, gramática, escritura, memoria, declinación, conjugación, sintaxis, verbalia, autores, sermón, acento y anotaciones. No olvida recomendar una lista de autores en prosa y poesía clásica tanto para el cultivo del hombre como para la dispersión de la mente.

La riqueza de Vives consiste en plantear un proyecto en el que se establecen los fines de la educación, exponiendo claramente los medios para su desarrollo.

Los apéndices son de incalculable valor, debido a que Leticia López muestra claramente la vigencia de los postulados vivistas, a través de su impacto en las obras de autores como Rousseau, Durkheim y Piaget.

\section{VALORACIÓN CRÍTICA}

Las sociedades en crisis, a lo largo de la historia, siempre han insistido en subrayar la importancia de la educación como fundamento del cambio. En este sentido, la lectura del presente libro resulta fundamental para pedagogos y maestros de todos los niveles de enseñanza porque, así como ocurre en nuestros días, durante el Renacimiento se levantaron numerosas voces que clamaban por una reforma profunda en la educación en general y en la enseñanza lingüística en particular. El humanismo renacentista y el contemporáneo se fundan en principios semejantes: el hombre como ser lingüístico y, por tanto, histórico, requiere desde sus primeros años de una sólida formación cimentada en el conocimiento de la lengua, entendida esta no solo como objeto erudito de estudio gramatical, sino especialmente como vehículo de comunicación y vinculación social.

Vives parte del hecho innegable de que nada evidencia con mayor nitidez la condición humana como el lenguaje y postula que el conocimiento del idioma, en este caso el latín, posee dos finalidades: mejorar la capacidad de lectura de autores de alto contenido formativo, es decir, de los clásicos, y posibilitar las condiciones de comunicación y 
diálogo entre los seres humanos. Así, escribió una gran cantidad de trabajos en los que expone este ideal educativo con la expectativa de contribuir a mejorar la sociedad de su tiempo. La autora los describe y analiza con rigor filológico y con la mirada humanística de quien vive en una realidad que exige también una profunda reforma de la enseñanza, especialmente en torno a las cuestiones que contribuyan a forjar y formar la inteligencia.

Es de gran beneficio leer el texto de la doctora López Serratos, pues en unas cuantas páginas explica cuidadosamente los postulados más importantes del pensamiento pedagógico del autor, postulados que muestran a uno de los más importantes representantes de un movimiento intelectual trascendental para la historia de la educación y de la pedagogía - como lo es el humanismo-, que todo estudioso de la educación debe conocer, pedagogo o docente de cualesquier nivel educativo, debido a que las experiencias ahí expuestas pueden mejorar sus prácticas y lo llevarán a querer adentrarse en su pensamiento. Su lectura es también benéfica para docentes de idiomas, debido a que Vives enseña cómo apoyarse en el estudio de la lengua vernácula para el aprendizaje del latín, idioma que bien puede ser una lengua viva.

Con este texto, que representa una excelente introducción al estudio del pensamiento pedagógico vivista, el lector podrá remitirse, con una guía segura, a las fuentes primarias vivistas siguientes: Pedagogía pueril, Contra los pseudodiálécticos, Paries palmatus, y por supuesto, Tratado de la enseñanza. 